\title{
$\widehat{A}$ Madridge \\ madridge Journal of Vaccines \\ Interconnecting Scientific World
}

Editorial Article

Open Access

\section{What have We learned from the Current Measles Outbreaks to prevent Future Vaccine-Preventable Emergencies?}

\author{
R Burciaga Valdez
}

Professor, Department of Family \& Community Medicine and Economics, University of New Mexico, Albuquerque, New Mexico, USA

\section{Article Info}

*Corresponding author:
R Burciaga Valdez
Professor
Department of Family \& Community
Medicine and Economics
University of New Mexico
Albuquerque, New Mexico
USA
E-mail: rovaldez@aol.com

Received: May 6, 2019

Accepted: June 24, 2019

Published: July 2, 2019

Citation: Valdez RB. What have We learned from the Current Measles Outbreaks to prevent Future Vaccine-Preventable Emergencies? Madridge J Vaccines. 2019; 3(1): 86-88.

doi: $10.18689 / \mathrm{mjv}-1000119$

Copyright: (c) 2019 The Author(s). This work is licensed under a Creative Commons Attribution 4.0 International License, which permits unrestricted use, distribution, and reproduction in any medium, provided the original work is properly cited.

Published by Madridge Publishers
Keywords: Measles; Outbreaks; Unvaccinated; Herd Immunity; Exemptions

The current U.S. measles outbreak is part of a global health crisis. The World Health Organization recently has called for global actions to curb measles outbreaks across the globe but in particular in India, China, Japan, Philippines, Thailand, Ukraine, and Israel [1]. The resurgence of vaccine-preventable diseases, particularly measles, poses a severe threat to the health of the public worldwide because of its highly contagious nature and severe long-term consequences. In Europe and Israel, similar outbreaks have led to health authorities proposing fines for parents who do not vaccinate their children.

In the United States, pockets of unvaccinated children, due in large part to religious and philosophical exemptions to laws requiring childhood vaccinations, continue to feed the 2019 outbreak, which has reached over 981 cases and is increasing. International travel to countries with measles outbreaks poses a threat to all communities, both domestically and abroad. Thus, the United States can no longer think of ourselves and our communities as isolated from the global community. In 2000, the U.S. Centers for Disease Control and Prevention declared victory over measles in the United States. Our current situation reveals the perils of overconfidence and a lack of global consciousness in relation to infectious diseases. Measles kills despite the availability of a vaccine that is safe and effective. In 2017, over 110,000 measles-related deaths were reported globally, an $80 \%$ decrease since 2000 due to the vaccination efforts in many countries. However, in 2019, the United States saw 981 individual cases in 26 states between January 1 and May 31, 2019 - the greatest number reported since 1992 [2].

In many neighborhoods, vaccination rates have fallen below 90 percent, well below the recommended 95 percent target crucial to maintain herd immunity. For example, in New York City's Brooklyn not only ultra-Orthodox Jewish schools have experienced these declines, but reports suggest that several Muslim schools, Bible-centered Christian academies, and other private schools such as those following the Waldorf education movement have vaccination rates that pose a threat to others in their communities. Public schools are obviously also at risk.

Inaccurate and deceptive media and public discourse related to vaccinations are one of the primary factors in this recent resurgence of measles. Misinformation is readily available on the Internet and promoted by local political leaders and other antivaccination proponents (i.e., the "anti-vaxx" parents). For example, Rep. Jonathon Strickland, a state legislator in Texas, called vaccines "sorcery" in a social media post. He compared government involvement in vaccinations to communism, saying "Vaccines are dangerous," despite all scientific evidence indicating the contrary [3].

Yet, some parents in the US remain unconvinced of the perils of preventable childhood diseases to their children and other members of their communities. Other 
parents choose not to immunize for fear of the vaccine's potential side-effects, real and imaginary. Some medical providers may be contributing to the problem by assisting these parents in avoiding vaccinations, perhaps because they are trying to honor parents' role in making decisions for their children or because they are unaware of the severity of the disease for their patients and their communities. Children infected by measles during these outbreaks may be at risk, although rare, for future illnesses as they age. After recovery from the acute illness, measles can continue to cause harm. Subacute sclerosing panencephalitis (SSPE), a fatal central nervous disease, could develop seven to ten years after a bout with measles. SSPE causes swelling of the brain, loss of cognitive abilities and death. So, some parents must be compelled to immunize their children using fines, restricting movement and other public health authorities, such as closing schools or quarantines.

In response to recent New York Times reports on measles outbreaks, some readers have shared their personal experiences about the perils of infectious and contagious diseases, such as measles, that may suggest how we might move forward to prevent future outbreaks.

A NY Times reader from San Francisco wrote:

"I also predate the vaccines and had all the now covered diseases. I can still remember the days in bed in a darkened room with measles, the incredible itching with chicken pox, the pain of the mumps and coughing so hard I cracked a rib with whooping cough. I don't understand why parents would take the chance to inflict all this pain on their children. And measles can be fatal to a baby or to a child, who contracts it.

There should be a way to make the anti-vaccine parents and people like Robert Kennedy Jr. who proclaim false science responsible for the anguish and possibly deaths they inflict on innocent bystanders.

At the very least, schools need to publish names of the families who do not vaccinate their children. Yes, I know that sounds draconian and yes, I understand why, for medical reasons, some children cannot be vaccinated. But many dangerous things in our world are labeled as "Hazardous to Health". If a child, or an adult can spread a disease that might kill someone, that is information that should be easily available to their communities."

\section{Another NY Times reader from New Mexico wrote:}

"I've had red measles, German measles, mumps, chickenpox and polio. No vaccines were available. I got through the first four, but the fifth was the glitchy one. I ended up in an iron lung, paralyzed from the neck down, and hospitalized for 5 months. I've lived with a disability for 70 years. Amazingly, I'm told by antivaxxers that "natural immunity" is best. Really?"

Finally, another NY Times reader from New Jersey expresses her fears and frustration writing:

"This makes me so angry. I am 6 months pregnant. I was vaccinated as a child, but found out at the onset of this pregnancy that the vaccine wore off and I am no longer immune. I am not able to get a booster until after my baby is born. Thus, I am forced to confront the risk of infection and the damage that it could cause to my unborn child when taking public transportation or even a taxi, going grocery shopping and visiting my doctor's office. My unborn child is completely vulnerable - and we had no choice in the matter. Furious with people who have made this choice for us."

Immunizations have worked so well that people have forgotten how severe vaccine-preventable infectious childhood diseases can be for those not vaccinated and for vulnerable community members, such as young babies not yet immunized, older people who are immune compromised, and others with medical conditions that prevent them from being vaccinated. It is clearly a public health challenge to convince the public of the current crisis in the absence of severe outcomes, particularly deaths. This is always the challenge for those of us who work in prevention. When our efforts work, the public fails to recognize what has been done to protect them against disaster. So, how do we sell wellknown prevention practices to skeptical political leaders and the public? Fundamentally, it is about trust in health authorities such as local public health departments or other health care providers [4]. We must work to earn the public's trust day in and day out, as trust is easily lost and difficult to regain. What can we do to build public trust so that our prevention efforts are received enthusiastically?

"Anti-vaxx" parents may not be convinced to change their opinions about vaccinations by facts alone. But, I suspect, most parents of unvaccinated children clearly want the best for their families, are unsure of whom to trust and may be open to educational efforts. We need a national campaign to combat misinformation and propaganda by "anti-vaxx" promotors and conspiracy campaigns. The current use of bots and trolls that spew false information must be countered directly if "vaccine shy" parents are to be properly informed and gain trust in what they encounter online. This is a great opportunity for the philanthropic community in the United States and non-profit health organizations such as the Robert Wood Johnson Foundation, the Pew Charitable Trust, Kaiser Family Foundation, the California Endowment, the Kellogg Foundation, and the David and Lucile Packard Foundation to combat online misinformation, particularly in high-risk counties where there are higher rates of unvaccinated children. This is also an opportunity for local community leaders to convey reliable messages that counter the toxic communication against vaccines.

The use of geographic information system (GIS) technologies can be used for enhancing our surveillance of vaccine-preventable diseases and identifying where public health resources should be deployed. For example, researchers at The Johns Hopkins University have used GIS to identify counties with the greatest risk of measles outbreaks in the U.S. [1]. They found that the greatest risk today is in Cook County, II; Los Angeles County, CA; Miami-Dade, FL; Queens, NY; and King County, WA. Many other counties are at risk, particularly those adjacent to areas with current outbreaks. In addition to offering weekly updates on outbreaks and their location, CDC offers on their website a toolkit for local/State Health 
Departments that contains useful information to answer public questions, augment department websites, and letter templates for parents, schools and health care providers [2].

We may learn (or relearn) lessons about influencing parental and community change by reviewing the work of those engaged in eradicating polio in India. The CORE Group Polio Project (CGPP) worked with the Indian government and non-governmental agencies to contribute to the eradication of polio [5]. They used social mobilization strategies to reduce family and community resistance to the oral polio vaccine. Such strategies required innovative messaging, building a sense of community ownership and empowering women, engaging local influencers, and recognizing the role of mobile populations in spreading polio. Fundamentally, their success, like other immunization campaigns, relied on building community trust.

Working with religious leaders to assist their congregations address concerns and provide accurate information has been a useful strategy for public health authorities in the past. So, similar pockets of opposition based on misinformed religious views reminds us that local health authorities must work with local religious leaders to promote vaccination. For example, in Brooklyn with a larger number of unvaccinated members of an Orthodox Jewish community that has been a hotbed for the current crisis in New York City, local Orthodox religious leaders must be part of the public health plan to vaccinate all children in their communities. Similarly, other religious and educational leaders must be part of the public health emergency response.

Social media and Internet search engines should demonstrate their corporate responsibility by screening out information related to vaccines that are clearly false and misleading and that causes harm to the public, just as they do for racist and pornographic content. We must applaud Facebook for rejecting advertisements with false vaccine claims. Search engines could similarly lower the rankings of websites that are clearly deceptive.

Clearly, education about the safety of vaccines alone is sometimes not an effective intervention. Outbreaks can be stopped using public health approaches such as immunizing contacts, preventing infected children and adults from participating in social settings and building up the "community immunity" network by vaccinating those around the index case.

States have created an environment for outbreaks by expanding vaccination exemption laws that include religious and philosophical exemptions, neither of which is scientifically nor theologically supported [6]. All 50 states have laws requiring vaccines for children attending school. Exemptions vary from state to state with 47 allowing for religious exemptions and 16 also allowing for "philosophical" exemptions, for those who object to immunizations for moral or personal beliefs.

"Congress shall make no law respecting an establishment of religion," but the second part of this amendment-" or prohibiting the free exercise thereof..."-is less clear, which has resulted in considerable legal and political debate. The First Amendment keeps the federal government from interfering with religious beliefs and practices and does not apply to the states. The Fourteenth Amendment, however, extended constitutionally guaranteed rights to the states, including religious freedoms. Few legal tests of the "exercise of religious freedoms" exist, but legal precedence generally holds federal law superior to religious practice. For example, in Employment Division v. Smith (1990) a public employee was fired for using peyote in a Native American Church ceremony and the Supreme Court held that the ban on such substances applied to everyone equally and that it would be unfair to recognize a private excuse and that to do so would undermine the law.

Today, the impact of current state laws regarding childhood vaccinations is being undermined by religious and personal exemptions. Given that there is no theological argument against vaccination but rather great support for vaccinations by all religious leaders around the world, states should move to rescind both religious and philosophical exemptions [7]. Washington State recently enacted legislation to end personal or philosophical vaccine exemptions for most parents whose children will attend daycare or school. But, the state has not eliminated exemptions for personal religious beliefs. West Virginia's Supreme Court, in Brown v. Stone (1979), approved the state's decision to deny religious and philosophical exemptions. For now, religious practices are subject to federal, state and local laws. The federal government should provide an incentive to states by setting conditions for education and health grants or other funding based on eliminating vaccination exemptions.

\section{References}

1. Sarkar S, Zlojutro A, Khan K, Gardner L. Measles resurgence in the USA: how international travel compounds vaccine resistance. Lancet Infect Dis. 2019. doi: 10.1016/S1473-3099(19)30231-2

2. Centers for Disease Control and Prevention (CDC). Measles Cases and Outbreaks. 2019.

3. Institute of Medicine (IOC). Adverse Effects of Vaccines: Evidence and Causality. Washington, DC: The National Academies Press; 2012.

4. Rolfe A, Cash-Gibson L, Car J, Sheikh A, McKinstry B. Interventions for improving patients' trust in doctors and groups of doctors. Cochrane Database Syst Rev. 2014. doi: 10.1002/14651858.CD004134.pub3

5. Dey R, Mahendra VS, Morry C, et al. Influencing Change: Documentation of CORE Group's Engagement in India's Polio Eradication Programme. Core India Group. 2019.

6. Valdez RB. Addressing the $21^{\text {st }}$ Century Challenges to Herd Immunity Madridge J Vaccines. 2019; 3(1): 77-79. doi: 10.18689/mjv-1000117

7. Egelko B. California's mandatory-vaccination law survives court test. San Francisco Chronicle. 2019. 